\title{
An Evaluation on Effects of Total Quality Applications in Customer Relations Management on Sustainable Global Competition
}

\author{
Pınar Altiok Gürel, $\mathrm{PhD}^{\mathrm{a}}$
}

${ }^{a}$ Faculty of Economics and Administrative Sciences, Beykent University. Turkey

\begin{abstract}
The concept of globalization inherently necessitated knowing management technics that could adapt to fast changes. Assuming all other financial aspects are almost equal for companies, the only factor "that can create difference" within the global competition environment is "the human factor". It draws attention in the way that among companies who set out with the same technical equipment, the companies who are successful in customer relations are able to render the global competition sustainable through approaches that are based on the human factor. In this area, the constructive influences of total quality management on the human, which is the main source that can manage information and turn it into speed and strength, positively reflect on companies and translate into advantages. Placing human at the center of the business, these approaches add new dimensions to changes and developments that will create differences in the global market in line with the versatile structure of business management and contribute to earnings that support economic growth.
\end{abstract}

Key Words: Total Quality Management, Customer Relations Management, Sustainable Competition, Globalization

\section{(C) 2014 Published by SSBFNET}

\section{Introduction}

As a result of developing technology and innovations in communications area realizing in line with globalization, the world market has almost become a single plane, and adopting the concept of quality has become the most basic strategy for companies to carry their business within ever-expanding market conditions. Quality goods and service production, besides becoming an obligation today, has also turned into a long-term investment factor that will earn brand image and prestige to the company. The fact that quality has become not the means, but the end for the company requires a re-structuring in all business functions, not merely in production units. At this point, the field that must be emphasized is the quality of customer relations within a company. Because, the concept of quality is effective in formation of both a customer-oriented corporate culture and an effective organization. After realization of the positive effects of Total Quality Management (TQM) on sustainable global competition in Customer Relations Management (CRM), it has been increasingly underlined and emphasized in the recent years that companies need application fields

\footnotetext{
${ }^{a}$ Corresponding author.
} 
Pinar Altiok Gürel /International Journal of Research in Business and Social Sciences Vol 3, No 1, 2014. ISSN: 2147-4478

for different management and marketing strategies. Mentioned effects will be examined in this study. Since the subject includes a multi-disciplinary approach, the effort of discussing the subject through various perspectives and within framework of current developments has arisen.

In the first chapter the concepts of quality, Total Quality Management and Customer Relations Management are generally touched upon and these concepts are evaluated within global competition context. In the second chapter, the EFQM Excellence Model, which is a current option within the process of forming an innovative strategy in terms of forming an innovative strategy within context of total quality management, is examined. In the third chapter, the new developments brought into competition conditions by the Information Age are specifically emphasized and then requirements of the CRM strategy for companies are examined. The subject of the fourth chapter is "customer value" which has recently gained currency as an important concept due to efforts of companies towards creating a difference and contributions of CRM in creating a customer lifetime value. Today, dimensions of the concept of dynamic qualities required to form the sustainable global competition environment have widened and this situation has reflected on the new understanding of marketing as a requirement for companies to design their dynamic abilities in a customer-oriented way. The fifth chapter of this study discusses this subject. The sixth chapter includes an examination of the "destructive creativity" concept, which is the working field of economics since J.A. Schumpeter, becoming prominent in creating customer value and its convenience for CRM, after it has gained currency with the level of advanced technology, is determined.

The relation between TQM and Human Resources Management (HRM) are also touched upon due to their functional relationship, which constitutes the seventh chapter of this study. At the final chapter, conclusions of the study are presented and various determinations are made on the subject together with a general evaluation.

\section{Discussing the Concepts of Quality, Total Quality Management and Customer Relations Management (CRM) Within Global Competition Context}

Quality is a concept with wide dimensions. The most basic description of quality is the level of goods' and services' meeting customer expectations. Surely it has a technical minimum standard. Conformance to these standards and specifications has been widened as "convenience of use", adding both tangible and intangible aspects to its meaning. Because quality also creates a perception of superiority in the customer, therefore forming a psychological effect. For this reason, beside the requirement of reflecting on all courses of the product, the concept of quality carries a special structure that is about a very wide area including perception, aesthetics and performance, reliability, scope of warranty and after-sale service stages.

The quality of a product is a compound of the dimensions of "design", "convenience" and "usage quality" which aims to meet customer needs in the most economic level possible and is a combination of all qualitative and quantitative factors (Taşkın, 2004:55-57). Improving the quality brings technical convenience in goods and service production, therefore decreasing stock and controlling costs (Teece, 2007: 1346-1347). 
Pinar Altiok Gürel /International Journal of Research in Business and Social Sciences Vol 3, No 1, 2014. ISSN: $2147-4478$

Total Quality Management (TQM) is a whole consisting of comprehensive, customer-oriented management and strategies (Erkılıç, 2007:52). TQM is a comprehensive and holistic management approach which carries its actions with a sense of responsibility that starts before production and includes post-production. It is not possible to achieve ethics where there is no quality, and it is not possible to achieve quality in the lack of ethics (Aktan, 2013:1). "Total Ethics Management" is a branch of TQM, and quality and ethics are complementary to one another (Aktan, 2013:1). Basic principles of TQM are "continuous improvement", "management of processes", "customer orientation", "highlevel importance on human resources management" and "total participation". The wording "total" within "TQM" includes all organizational functions and all persons in these functions, such as customers, suppliers and employees, before, during and after the production stage (Erk1lıç, 2007:52). Here the customer is placed at the center of all processes and the understanding of continuous improvement towards maximizing customer satisfaction is instilled into the whole team. The reason for this approach is that TQM is a special strategy for companies and is a management style which is reflected onto the company vision and infused to all employees.

The purpose in the TQM approach is training the employed personnel as individuals oriented to problem resolving. The objective in this context is to focus on conclusively resolving problems in a long-term perspective as they shall not recur in the future, rather than appealing to short-term perspective through temporary measures. Therefore the management mission of protecting and continuously improving the present, which is a requirement of total quality philosophy, is able to form a healthy structure. Quality starts with people and by this means it is reflected on all processes. Three basic building blocks of quality are equipment, software and the human, and the highest level of synergic gains to be formed by these three factors may only be benefited from when the human factor is processed correctly. For this reason, TQM is a culture which reflects the perspective of a company. Every factor that forms an input to the company in the total quality approach affects quality. Consisting of many valuable technics such as Fishbone Diagrams, Quality Circles, Kaizen Philosophy, PDCA Cycle, JIT, Six Sigma, Pareto Analysis, Brain Storm, GAP Analysis, Benchmarking, etc., the TQM is implemented for the purpose of providing high-level satisfaction to all addressees of the company, starting with employed personnel and customers. Also including various problem-solving technics, total quality approaches implement their actions for the purpose of presenting as many of options as possible for a specific situation or problem. And for this, it bears great importance to materialize teamwork.

Development of clear communication capacity, which bears vital importance in multiple environments, also reveals creative thinking abilities of individuals. Solution-oriented projects created as a result of approaches such as systematic team works and respecting personal experiences and creative abilities of team members while focusing on problems are translated into scientific data using various statistical analyses. Implementation of a so created project positively affects employees, fostering their perception of belonging through the realization that they are important parts of their company where their opinions are respected and they participate in management activities. This in turn creates social effects on employees such as increase in self-confidence, psychological and motivational support, learning to work as a team, ability to produce solution-oriented projects, advancing of personal improvement, increasing of communication skills, the perception of professing a meaningful work, the enjoyment of feeling as part 
Pinar Altiok Gürel /International Journal of Research in Business and Social Sciences Vol 3, No 1, 2014. ISSN: $2147-4478$

of an organization, team spirit and gaining new abilities, which reflect on corporate culture and therefore positively support productivity and efficiency of the company. With this aspect, total quality approaches, beside the commanding chairs that have developed as a result of the hegemonic image ongoing since the classic ecol, contribute to recognizing more humane traits through coaching in line with post-modern approaches, which integrate with the working personnel and develop projects with them, supporting their work.

The principal objective of a business is to increase profitability and productivity and in connection, decrease costs. Since high cost is a situation which frequently occurs due to low quality, total quality approach brings quite important contributions such as prevention of cost problem and enabling increases in productivity, in line with its principles of converging zero error and provide $100 \%$ customer satisfaction. Beside, since the continuous improvement works of TQM include measuring, feedback, problem-solving and continuous learning, this ability, to be earned by the company, contributes to resolving of errors and recurring problems during innovation process, therefore increasing productivity in resource utilization (Güleş \& Bülbül, 2004:120). On the other hand, it is obvious that creative thinking ability of the personnel is to be revealed in order to increase productivity. Due to their motivation-increasing effect, total quality applications bring about positive results for the company, such as decreases in work absenteeism and workforce turnover rate. The principle matter in total quality philosophy is to satisfy all social shareholders.

Today, while customers follow goods and services, they prefer corporations which, beside meeting certain standards, exceed expectations, respect their customers, invest for the future and provide full satisfaction during, and as well, after a sale. A company's success within the global competition environment depends on seeking for and sustaining new competitive advantages. In order to realize such matters, companies are required to work in the area of increasing their abilities to improve, change and innovate (Güleş \& Bülbül, 2004:115-116) within the context of achieving sustainable competitive advantage. At this point, companies may encourage innovation works, benefiting from uniting and improving management philosophy and principles of TQM (Güneş \& Bülbül, 2004:120). Beside, TQM also emphasizes that an effective environmental management is needed for sustainable development and environmental ethics is one of the basic dimensions of total quality management (Aktan, 2013:1). Considering that production, management and sale policies related to environmental protection specifically gained currency during the last term and that technological infrastructure is directed to works based on alternative energy sources aiming for environmental protection, in many areas starting with the automotive sector, it is obvious that environmental ethics will be an important factor in the future, in that it creates global competitive advantage. As a result of globalization, companies are able to procure other compounds related to technology and infrastructure, which can bring competitive advantage to them, approximately at the same level. However, the only factor that can create a difference is the "human" factor. For this reason, it is important to adopt the concept of quality in formation of a "unique" corporate culture which does not resemble any other and cannot be imitated. TQM defends competition-based organizations which are aware that it is necessary to integrate to the international market, knowing that the reality of globalization must not be overlooked in the way to creating an excellent organization (Aktan, 2013:3). In this new information-utilizing area where it is a necessity to provide the structuring that can adapt to the speed required by the process of change, companies are 
Pinar Altiok Gürel /International Journal of Research in Business and Social Sciences Vol 3, No 1, 2014. ISSN: 2147-4478

required to adopt strategies which centralize their customers, and therefore effective customer relations management, for the purposes of catching opportunities, utilizing technology in basic areas such as production-marketingorganization and internalize the concept of quality in all processes (Alt1ok, 2013:2). Because while it was the principal factor of development to have land, machine and other sources of income, in the Information Age the "human being" is at the center of all formations, starting with social and economic structures. It is the human, who produces, utilizes and manages information (Durukan, 2006:31).

In the Information Age, human is accepted as a being which has got the intellect and ability to reach all types of resources, including money - on the condition of possessing required education, experience and infrastructure- (Altiok, 2013:2). Therefore, utilization of information in business management technics affected production processes and the concept of management gained a new dimension through globalization. The fact that these new management styles, named as "Post-Modern Management Technics", are approaches that feature the human being drew attentions to these new methods. Specifically, these structures which gradually tend to adopt "flat" organization schemes, are becoming obliged to work in line with the philosophy of the quality concept, in order to stay functional in wider markets and form a customer lifetime value. Customer demands and expectations are among the basic factors that commence the change in companies which have adopted TQM (Güleş \& Bülbül, 2004:123). For this reason, the models "worker empowerment", "network type organization", "simple organization" are inclined to decrease layers, while in all current methods based on organizational downsizing the efforts are towards formation of the quality conditions wherein goods and services increase customer satisfaction during and after sales, costs are reduced and fast adaptation ability has been gained.

The zero-base management technic, which has intensely been coming fore recently and is named as "re-engineering" since it envisages re-structuring of a business through deep-rooted reform and transformation, forms common ground within the subject of "customer orientation", which is the basic factor of Total Quality Management, in essence. The objective of forming a business environment that will result in satisfaction of individual and organizational needs considering the human being as the most valuable resource and therefore achieving profitability and productivity, promoted gravitation towards the tools that provide motivation, which is the most valuable drive that will prompt the individual to work more efficiently in business management, therefore TQM applications re-gained currency. Because TQM applications include valuable motivators such as working personnel expressing themselves, being able to share their ideas and participate in the management. With the specific realization that decision-participating mechanism greatly affects morale and productivity, the importance of teamwork became evident and in this direction, it was understood that TQM applications foster the positive effects on the social system which has been sustained in companies. In companies, effect of the social system being implemented is more than that of the physical factors. Human Resources Management and Organizational Behavior, two very important disciplines of business management, took human behavior as base and elected to increase productivity from this point forward. With acceleration of globalization and innovations brought by the Information Age signifying the human factor, TQM applications drew 
Pinar Altiok Gürel /International Journal of Research in Business and Social Sciences Vol 3, No 1, 2014. ISSN: 2147-4478

attention as democratic formations fostering the information carrying and managing capacities of the human being, which is an intellectual capital.

The business administration, while it is able to constitute a formal organizational structure using various infrastructures and technology, it is obliged to manage the whole of relations developing within the organization in a way that cannot be predicted by formal organizations and affect profitability and productivity. In order to manage this structure, which generally originates from the relations among the personnel and between personnel and the environment and which cannot be preplanned, with the minimum possible damage and through formulas that would yield favorable results for the business, it is the human-based approaches that play a reinforcing role. At this point, efforts toward rendering factors such as ideas, objectives, beliefs, behaviors and culture as compounds for formation of a company-specific identity accelerate the process of influencing individuals for taking action, therefore enabling formation of organizational motivation. In this way, works aiming to transform informal structures into conscious designs find their place especially in the CRM area, and TQM technics thoroughly fit in this structure in terms of its philosophy. The definition of "Customer Relations Management (CRM)", which is a quite far-reaching concept, is "combination of strategies and technologies which develop communication-establishment programs, and re-structure the whole organization for focusing on customer satisfaction" (Mucuk, 2009:13).

Customer relations management is an approach which aims to understand behaviors and values of different customers, obtain information about customers and increase efficiency of such information (Tekin \& Çiçek 2005b:66). The new dimensions formed by globalization brought about the understanding of modern marketing and therefore marketing was comprehensively defined as the planning and implementation process about "developing", "design", "pricing", "promotion" and "distribution" of goods and services in order to realize individual and organizational objectives (Mucuk, 2012:120). Thus it is expressed that this process consists of factors which start before production with information gathering and design, continue after sale and complement each other. Therefore it is possible to say that the modern understanding of marketing as a management philosophy which realizes the profitability objective of a business by highlighting consumers and consumer satisfaction is focused around three main factors, namely customer orientation, integrated marketing activities and sales volume providing long-term continuous profits (Mucuk, 2009:8). By taking customer satisfaction as base, the company will be structuring its strategy such that market analysis and product planning and development works reach the highest level of customer satisfaction, therefore creating a customer value that will both reflect on customer loyalty and long-term profitability. To this end a company needs a comprehensive customer relations management infrastructure based on sturdy foundations. CRM is an informationintense management system (Güleş, 2004:241).

CRM utilizes advanced planning and prediction tools in order to maximize the relationship between customer and income, therefore connects all elements and processes of multi-tow demand chains to the source chain. Thus integrated solutions intended to achieve and increase customer value are found and customer satisfaction is ensured. The objective in CRM is to code all relationship of customers with the company or the brand, place these codes into 
Pinar Altiok Gürel /International Journal of Research in Business and Social Sciences Vol 3, No 1, 2014. ISSN: $2147-4478$

huge data warehouses, reaching conclusions using gathered information (Özmen \& Özmen, 2002:2-3) and utilizing these conclusions in such a way to increase profitability, using information technologies. When a company implements CRM, it determines via rational strategies the demands and needs of customers. Utilization of "re-selling", "up-selling" and "cross-selling" technics maximizes total life span of customers. Areas of campaigns, logistics, product order, stock costs and all other areas related to management of company properties are optimized, thus providing productivity increase. In management of these areas, which bring competitive advantage to the company, utilization of TQM technics within CRM, general image of customers in areas related to goods and services produced, such as availability, communication, transparency, flexibility and responding is supported and in addition, advantages are gained in getting the customers to positively perceive criteria such as after-sale support, competence and behaviors of personnel, customers' inclination to follow the service or product in the future and desire to recommend the corporation to other potential customers (Erkılıç, 2007:53).

The purpose of a company is to provide customer continuity. The factor to enable achieving of this objective is the quality of customer relations management. Effective development of customer relations can be achieved through internalization of quality in all fields and stages of the business as a long-term philosophy. In other words, quality is an awareness of responsibility which must be regarded throughout the period of sale and after-sale, rather than merely during sale. Beside the necessity of providing a certain level of standard technically, it is especially important for companies to go quite beyond that and transform the concept of quality, which every customer defines and determines according to their own perceptions and expectations, into a corporate culture which can treat quality within its unique dynamism. For this, it is necessary to form company strategy based on very well-analyzed customer demands and expectations, therefore instilling a strong quality perception in the customers' minds while standing out among the rivals. Efforts spent in global conditions for purposes such as entering new markets, increasing sales and profitability and expanding market share brought forward the concept of "catching global dynamism without losing locality" as a difference. This tendency, which is followed by a reference to the concept of global entrepreneurship, is born from needs of the companies to position their strategies as aimed at the world market in order to extend to new markets. To this end, "quality" within CRM has been the most important factor, which reflected on all production and marketing policies of a company. For this reason, the whole strategy of a company intending to realize its objectives should be formed in line with quality principles. The fact that quality is a concept that brings continuity necessitates a planned corporate culture both in terms of personnel communications within the corporation and of the company to establish effective relations with all of its shareholders in touch, starting with its customers.

Conducting a healthy team work is also related to employing personnel having qualifications in line with the quality philosophy adopted by the company. Effective and productive utilization of company resources while preserving the objective of quality, and together with this, internalizing quality in virtually all units of a company depends on such formation of corporate culture. Increasing quality will reflect on customer satisfaction and loyalty. Company profitability depends on customer retention rate. Research results show that a $1 \%$ increase in customer satisfaction brings an approximate $12 \%$ increase in investment return, a $5 \%$ increase in current customer retention rate translates 
Pinar Altiok Gürel /International Journal of Research in Business and Social Sciences Vol 3, No 1, 2014. ISSN: $2147-4478$

into a profit increase of $25-125 \%$, and a $1 \%$ increase in customer satisfaction may increase the customer loyalty rate by $10 \%$ (Koç, 2013:ii). Considering the fact that gaining new customers is 5 times more costly than retaining current customers (Koç, 2013:ii), retention of current customers is a sensible approach. The context between quality and cost in global competition stands out as specifically including the factor(s) of speed and/or timing. Considering the everchanging expectations of customers, capacity of a company for faster product development and meeting customer expectations will affects its advantageous position within the competition environment. For this reason, improvement, management and finally, supervision of processes greatly emphasized within total quality management are of vital importance in the company's quest to achieve the state of zero error and maximize customer satisfaction. New developments contributed to the world market by globalization obliged companies to develop strategies that could welcome changes in order to achieve sustainable competition. In this regard, considering the inherent structure of total quality management which requires change, vision, mission, values and principles of a company should be defined both in relation with its CRM strategy and its total quality approach. Utilization of total quality approach both in public and private sectors means an increase in welfare which shall reflect on all aspects of social life.

\section{EFQM Excellence Model in Total Quality Management}

As the company achieves continuity in quality applications and matures in this regard, it will be in need of an inclination to implement more comprehensive technics which will further its present situation (Balbastre \& Canet, 2011:5). Originating from TQM, EFQM Excellence Model is a newly emerged model which is used today for increasing company performance, and its successful implementation depends on a thorough understanding of the basic concepts of total quality. EFQM means "European Foundation for Quality Management". The EFQM Excellence Model is a model utilized to encourage corporations to achieve sustainable excellence independent from sector, size, structure or development level and a tool which shows companies their progress point in the way to excellence, helps them determine their shortcomings and prompts use of certain approaches for reaching suitable solutions (Argüden, 2013). The EFQM Model constitutes an option for the company in order to adopt the process of forming a holistic strategy in terms of contributing to the sustainable competition advantage (Balbastre \& Canet, 2011:1). Therefore as companies gather more experience they will be able to contribute to development of innovative strategies and new perspectives directed to sustainable competition by adopting utilization of EFQM Excellence Model which is fartherreaching since it requires a more cumulative and detailed study (Balbastre \& Canet, 2011:5).

According to the EFQM approach, the factors determined as basic concepts of excellence are defined as "Taking Responsibility for a Sustainable Future", "Formation of Collaborations", "Feeding Creativity and Innovation", "Achieving Together With Employees", "Managing Within Processes", "Visionary, Inspiring and Holistic Leadership", "Creating Value for Customers", and "Realizing Balanced Results" (Kalder, 2013). These concepts constitute the foundation needed by a company to achieve sustainable success and also form the common language of senior management, using essence of the factors required for an excellent corporate culture (Kalder, 2013). The essence of EFQM Excellence Model holds the idea that abilities of employees are transformed into business outputs 
Pinar Altiok Gürel /International Journal of Research in Business and Social Sciences Vol 3, No 1, 2014. ISSN: $2147-4478$

by utilization of various processes. That is, employees and processes are inputs which produce results within business life. The EFQM Excellence Model consists of 9 main criteria, 5 of which are inputs and the remaining, outputs. Input criteria of the EFQM Excellence Model are; "leadership", "defining and implementation of policies and strategies", "activation of employees through effective human resources management, human resource planning and healthy performance valuation systems", "effectual utilization of company resources such as human-information-technology, which can be collaborated" and "definition and sustaining of processes in a result-oriented approach" (Kılıç \& Türker, 2005).

The output criteria of the model consists of measurements related to "customers", "employees", "society" and "financial and non-financial performance results" (Kılı̨̧ \& Türker, 2005). The model comprises of a system named "RADAR", which consists of four dimensions, namely; "Results", "Approach", "Deployment" and "Assessment / Review". The fact that EFQM Excellence Model is a "self-evaluation" tool for companies (Argüden, 2013) distinguished the model within the global competition environment. "Results" are caused by "input" and "input" is improved upon the feedback obtained from "results" (Kalder, 2013). The result criteria indicate what is realized by the corporation. It is possible to properly assess the corporate excellence degree of any corporation by using RADAR (Kalder, 2013). Here, basic factors directed to process improvement, such as learning, creativity and innovativeness which can bring competitive advantage, can be understood by connecting cause-effect relations, therefore they can be used as beacons in project management. The agenda is that companies utilizing EFQM Excellence Model yield performances greater than industrial averages in terms of profitability and stock market value, therefore utilizing greater competitive power (Argüden, 2013).

Excellent corporations design, manage and improve processes, products and services for the purpose of creating an increasing value for their customers and other shareholders, therefore products and services are improved as to create the most suitable value for customers (Kalder, 2013). Customer relations are also managed and improved in line with such an excellence understanding (Kalder, 2013). In this context, the position and importance total quality in customer relations in terms of a sustainable global competition are more important in lifting and differentiating the company to a higher level.

4. Distinguishing of Customer Relations Management through Perception of Information, as a Source of Competition in the New Economy, in a Different Dimension

The reason for the concept "New Economy" having become a center of attention recently is migration of learning processes to different areas and dimensions as a result of changes in information technologies. The new economy regards intangible, dynamic and procedural resources such as information and abilities as the most important competitive power (Koçak, 2012:68). A brand new process has started in the business management area especially after post-modern management technics gained currency. 
Pinar Altiok Gürel /International Journal of Research in Business and Social Sciences Vol 3, No 1, 2014. ISSN: $2147-4478$

The person who is able to manage information has individually turned into a principle economic input and social life has re-structured around an information center (Alt1ok, 2013:6). Especially after 1980s when the foundation of competition migrated from tangible assets to intangible assets (Koçak, 2012:63), the age of "new economy", where information is positioned at the center of the system and yield of the human investment became higher than physical capital investment, accelerated forward.

The marketing sense where the company is dominant and customer is rather in a passive position has become different since education level of consumers increased and information accessibility was facilitated and the concept of acquiring competitive advantage by creating a value for customers has become a strategic understanding for companies. In other terms, the basic paradigm of marketing activities until 2000s was the understanding of change which includes a shortterm practicality (Üner 2003) and a company in a rather active and directive position.

The new economy has brought a mutual economy wherein consumers are also able to utilize information technologies and easily access information, rather than a unilateral economy wherein information technologies were only used by companies and information asymmetry was in business' favor (Koçak, 2012:77). Therefore, the profitability, which can be achieved in the years after 2000 by creating customer value by establishing long-term customer relations, became a target in line with the requirements of the new economy understanding. The essence in this context is institutionalizing the understanding of sharing the same common ground with customers and regarding them as solution partners at the same side. At this very point, supportive role of total quality efforts came fore and the understanding that the concept of quality will provide a different perspective which would bring global competition advantage, gained recognizance. Because in this new economy, the change focused on unilateral products lost its meaning and a new structure of understanding wherein consumers sought solutions for their perceived needs rather than seeking products, and new and different values were created for consumers by provision of required resources that would provide solution to customers, started dominating the markets (Koçak, 2012:77).

Companies able to reflect this sensibility to their strategies would be able to achieve sustainable competitive advantage. For this reason, to include implementations which enable TQM within CRM as a business management discipline centered around a human-oriented sense, will form an important part of the system. In this new informationoriented order, technology, equipment and software used in processes starting from customer acquiring, through product and service presentation and provision of customer continuity and loyalty, must be designed in a way that enables adaptation to innovation and bring competitive advantage through improvement of customer relations using modern methods (Özmen \& Özmen, 2002:2-3). Because, since both the company and the customer are able to easily reach information, the value to be formed needs to be uncovered through collaboration with the customer. Companies are expected to question the level of their competence and position within the competition and accordingly develop strategies in order to create this value (Koçak, 2012:65). Evaluation of global competition strategies at this focal point is a requirement of the new economy. Realization of the objectives of CRM applications in mass markets depends on obtaining, analyzing and processing customer information and transferring of such information to units within and out 
Pinar Altiok Gürel /International Journal of Research in Business and Social Sciences Vol 3, No 1, 2014. ISSN: $2147-4478$

of the organization on time and in a cost-effective way (Güleş, 2004:241). For this reason, the importance of adding value to information and immediate information retrieval when needed should be specifically highlighted in CRM (Özmen \& Özmen, 2002:1). Therefore, today it is a requirement to utilize marketing and technology in a way that will provide sustainable competitive advantage for companies. Another important differentiation is that, in connection with information being the most important resource of competitive strength, while the market environment is regarded as a factor which cannot be controlled and to which a company must strive to adapt, market environment is considered as a proactive source in the service-dominant marketing sense (Koçak, 2012:68). For the integration intended at this point, it is quite important to provide a structure that will be able to develop close relations with customers. Within this context, continuous gathering and analyzing of information pertaining to customer needs and demands is a key factor both in achieving a sustainable competitive advantage and successful implementation of CRM (Güleş, 2004:241). At this point, achieving successful results depends on marketing managers' ability to correctly direct information processors (Özmen \& Özmen, 2002:8) and to make correct decisions to this end. For this reason, entrepreneurs in an information society should be equipped to thoroughly analyze the relationship between internal and external parameters and therefore capitalize on the change with maximum benefits and minimum damages (Durukan, 2006:31).

\section{The Concept of Customer Value as a Sustainable Global Competition Tool and Contributions of Total Quality Management in Creating a Customer Lifetime Value}

Businesses create value out of their properties and transfer this value (Bakırtaş-Yılmaz-Özman-Barış, 2013:72). Customer value is the difference between total customer value and total customer costs (Bakırtaş-Yılmaz-ÖzmanBarış, 2013:72). In other words, customer value is the ratio of customer benefit in an exchange operation against the amount paid/sustained by the customer. The value perceived by the customer does not only consist of tangible benefits and factors such as reliance, fame and the level of reliability and relationship (Tekin \& Çiçek, 2005b:66) are also discussed within this scope. Therefore, the factors of total customer value being product value, service value, personnel value and image value, total customer cost consists of monetary cost, time cost, energy cost and psychic cost (Bakırtaş-Yılmaz-Özman-Barış, 2013:72).

Creating customer value is to provide the customer more than their expectations against their payment, that is, presenting additional value to the customer without any payment (Odabaş1, 2006:18). This additional value presented to the customer induces formation of a psychological bond between customer and the company. As a result forms the customer loyalty concept, which occurs as the process of customer continuing to purchase from the respective company and exponentially increasing such purchases, which concept is quite precious for companies. Against a plethora of products and options, the customer naturally will select the company which presents the highest customer value. In other words, creating value is a synthesis of service and quality and this concept covers all aspects of customer satisfaction (Tekin \& Çiçek, 2005b:66).

Creating value is an important factor utilized for providing competitive advantage. Likewise, companies will try to create customer value by presenting goods and services which include an offer/a content different that those of 
Pinar Altiok Gürel /International Journal of Research in Business and Social Sciences Vol 3, No 1, 2014. ISSN: 2147-4478

respective rivals. Companies are required to define how they will create customer value, which is the superior quality of their current alternatives (Bakırtaş-Yılmaz-Özman-Barış, 2013:72). Since the roles played by both marketing and quality are important within the process of creating and conveying customer value, evaluated are two high-level aspects within the value offer of a company (Bakırtaş-Yılmaz-Özman-Barış, 2013:72).

Value creation is a strategic process for a product, service or business unit to grow and manage its competitive share and customer value management must be evaluated in terms of strategic competitive advantage since it enables the improvement aimed in customer services. While customer satisfaction focuses on satisfaction of the people utilizing the company's goods and services, the approach of providing value to a customer focuses on how the customer makes their selection among respective rival companies (Tekin \& Çiçek, 2005b:67).

The ability of companies to present goods and services that can create value for their customers depends on them to know their customers very well. Especially the facts that evaluation on the cost paid and benefit received is up to customer perception and that it is difficult to make a determination due to personal differences in this regard, brought about proceeding without leaving any voids and therefore utilizing approaches related to raising the quality bar, specifically in regard to service quality. Because, customer satisfaction can be formed by filling of certain voids which can be expressed as "service quality voids" and service quality is affected by five types of void groups namely "listening", "service design and standards", "service performance", "communication" and "customer void" and these voids guide the company for determination of standards it is expected to reach, which raises the bar of the quality understanding and of objectives (Zeithaml \& Bitner \& Gremler, 2009:40-47). This situation means a high-level satisfaction directed to customer expectations and getting good results towards providing the customer satisfaction to form in line with that satisfaction. The customer void specifically occurs due to a combination of negative effects of the other four voids. If the service provided by the company and the performance level perceived by customers result in a negative difference from the customer's perspective, then it means a customer void is forming. For this reason, in order to avoid such voids within the global competition environment, it will be a sensible manner to correctly use and time the total quality methods and thoroughly analyze customer expectations, followed by accordingly determining service quality standard. For this reason, including the personnel tasked in units that are not in face to face interaction with customers is important for the whole process to operate healthily, for service businesses. In other words, the employee will be sharing the responsibility in reaching all personnel quality standards and formation of services that can completely satisfy the customer (Zeithaml \& Bitner \& Gremler, 2009:685).

The fact that TQM applications are based on teamwork provides and advantageous structure in this regard. Requirements for achieving advantage in global competition are; to create customer value, to provide customer satisfaction in a way that translates into customer value and to form customer relationships in a way that will bring a customer lifetime value. Customer-orientation, a strategy that brings companies into an advantageous position in global competition, is a cultural fashion in $\neg$ a company wherein the company manages all its processes and activities directed towards providing high-level value for customer for the purpose of sustaining long-term profits (Bakırtaş- 
Pinar Altiok Gürel /International Journal of Research in Business and Social Sciences Vol 3, No 1, 2014. ISSN: $2147-4478$

Yılmaz-Özman-Barış, 2013:70). This culture necessitates a deep understanding of customers, customer activities, interests and thoughts around certain values and resolutions provided by the company (Bakırtaş-Yılmaz-Özman-Barış, 2013:70). During creation of the value to be presented to the customer, the respective value must be increased while the costs must be decreased (Ünnü, 2009:1250). For a company to manage customer relations based on the foundation of "customer value" and establish and develop value-creating relations with its customers, it has to fulfill seven interrelated management principles. These principles can be summed as; "considering the customer as the center of the works done", "managing the works from the perspective of customers", "conducting quality works", "keeping relations lively", "softening problems", "transforming customer satisfaction into determination" and "checking developments through continuous observation” (Bakırtaş-Yılmaz-Özman-Barış, 2013:75).

The customer satisfaction acquired as a result of creating value for customers provides competitive advantages to the company such as repetition of purchases in larger amounts, increasing of profit margins due to more consciously managing costs and expenses, employee motivation increasing due to creativity being promoted, and in addition, decrease in workforce turnover rate, customer who received customer value due to high level of satisfaction becoming loyal customers and sharing their experiences and consequently bringing in new customers. The new approach in marketing idea is that today value can only form out of acting in cooperation with customers and providing resources that will create value for the customers, and that the product is only a mechanism through which services are provided (Koçak, 2012:66). Today, the fact that customers tend to perceive the act of purchasing as an experience toward hedonistic enjoyment as an extension to hedonistic consumption, which has gotten widespread recently, specifically moved the concept of customer value into currency. So much so that, due to customers' expectations that their needs be immediately fulfilled and their tendency to prefer companies that provide the highest total value for them (Odabaş1, 2006:18), approaches directed to creating customer value have become an important factor in differentiation and global competition strategies for companies. The actual objective in total quality approach is to provide a complete customer satisfaction.

Considering that customer satisfaction is a factor that comprises of a comparison between the performance perceived by the customer and fulfillment of customer expectations, (Mucuk, 2009:12), in this situation, using TQM approaches within CRM, which is the combination point of such concepts, is the result of a necessity. Because, in addition to customer satisfaction factors, customer value examines the selection among rivals, comparison of selection criteria with those of respective rivals and importance degrees of each criterion (Odabaş1, 2006:18) and value creation forms out of cooperated actions of the customer and the company (Koşak, 2012:66). At this point it is possible to consider total quality methods as a reinforcer which roofs all of these concepts. Creating value for a customer, for the company, portrays the gains of the respective customer after purchasing and using the good or the service and how the company is perceived by the customer. For example, within the famous fourteen principles of Edwards Deming, who has an important place in TQM, which principles emphasize creating continuity in objectives and continuous system improvement, the main focus point is defined as to create customer value, and the necessary approach is defined as; continuously working to understand the customer defines quality, define your customers and learn what they demand, 
Pinar Altiok Gürel /International Journal of Research in Business and Social Sciences Vol 3, No 1, 2014. ISSN: 2147-4478

develop criteria as to determine the level of customer satisfaction and improve the processes affecting these criteria (Vikipedia, 2013). Better fulfillment of customer demands and increasing customer attachment to the company will be possible through formation of strong customer relations. This is possible through a long-term view which aims for ever-repeating purchases of the customer. Also named as "relationship marketing", this perspective is only possible through healthy implementation of CRM and customer lifetime value, by companies. A company is to turn its customers into loyal customers by increasing customer satisfaction through the approach of quality. Developing such strong relationship with customers necessitates proximity to customers and a healthy information gathering process. For these objectives, a customer database must be formed.

The concept of "customer value" brings an approach which is expressed as "customer lifetime value" and covers a longer range dimension. The customer lifetime value can be described as the situation wherein the company perceives the customer as a certain type of solution partner in a lifelong relationship and acting in line with this situation. The real customer value and customer lifetime value are equivalent concepts. Customer lifetime value is the net present value of future flows to be expected from the lifetime purchases of a customer. Customer lifetime value formation is; i) data analysis for a suitable segmenting process and data analysis for database marketing, ii) automation process of decisions against the decisions of determining customer demand, targeting retention activities and ordering retention activities according to lifetime customer value, iii) definition of customer categories for cross-selling and up-selling of financial services, iv) developing the portfolio of goods and services ordered for customer lifetime value, v) direction to the customer the channels in line with customer lifelong value (Bakırtaş-Yılmaz-Özman-Barış, 2013:72-73).

Considering that company profitability depends on customer retention rate, forming and sustaining a customer lifetime value requires a serious management skill set. In a long-term consideration, the cost of working with a satisfied customer is lower, and the profits acquired from such customer are higher for the company. The important point here is the fact that the authority to assess the level of the presented value is the customer. Therefore, the company focusing on its present customers / solution partners and working to retain the customers within this group will be an extension of this perspective. In this sense, it is surely inevitable that a company must maintain its activities for all customer groups. However, while all customers are important for a company, they do not carry the same meaning. Thus the recent effects of globalization compelled works in CRM aimed to expand market share of companies, especially to focus on developing strategies towards increasing customer share. At this point comes in the "Pareto Principle", which is still being used in parallel with the developing technology level. According to Pareto's famed $80 / 20$ rule, $80 \%$ of sales comes from $20 \%$ of the customers (What is $80 / 20$ Rule, 2013). In other words, according to this rule, the company acquires $80 \%$ of its profits from a $20 \%$ of its customers. For this reason, companies follow strategies in order to avoid losing this customer group of $20 \%$. Being quite important in terms of customer satisfaction, these customers are of capital importance for the company in terms of the profitability they provide and their potential to being in new customers. In addition, thanks to data gathering reached today, there are also efforts to provide customer loyalty in the remaining $80 \%$ group of customers. Besides, the Pareto Principle forms the basis for the Pareto Graphic, which is one of the key tools for "Holistic Quality Control" and "Six Sigma" management within TQY (Rushton \& Oxley \& 
Pinar Altiok Gürel /International Journal of Research in Business and Social Sciences Vol 3, No 1, 2014. ISSN: $2147-4478$

Croucher, 2001:107-108). Again, applications such as "ABC Analysis" and "XYZ Analysis" used in continuous improvement works such as transportation, stocking, product optimization, adjusting carrying costs and procurement, which are of principle objectives of TQM, act on the Pareto Principle (Rushton \& Oxley \& Croucher, 2001:107-108). Thus this principle is incorporated in works directed to increase sales and customer satisfaction. The ability of consumers to easily access information altered the traditional system wherein customers depended on companies to procure information about products and market and companies directed purchasing activities, that is, the information asymmetry between customers and companies has become different.

The customer is no longer a source that is processed and has become a source that generates processes, the "change value" has lost its place to "use value" in the new paradigm, and in the new paradigm, the customer is no longer defined as a source for whose needs products are developed and which can be influenced, but is now defined as a source a source of cooperated action which generates processes (Koçak, 2012:61). Within the market conditions brought about by global competition, all companies are in a situation to create value for all of their shareholders, not just for their customers. In this sense, competitive power with new information technologies has been enabled through collaborative works of companies and customers. In order for companies to maximize customer lifetime value, customer value must be created and companies must strive to retain and improve customer base using up-selling and cross-selling potential. Customer retention actions must be also applied for customers who made a purchase a long time ago. According to a research, replacing a previously-lost customer costs a company ten times more time, money and energy (Bakırtaş-Yılmaz-Özman-Barış, 2013:75). In addition, a 2\% increase in a company’s customer retention rate may induce a 10\% decrease in general expenses (Bakırtaş-Yılmaz-Özman-Barış, 2013:75).

Diminishing differences between brands and abundance of similar goods and services in the market compelled companies to focus on behavioral approaches rather than creating loyalty by fulfilling customer needs, therefore changed company actions into establish emotional connections with customers in order to created emotionally attached customers (Gobe, 2009:189). At this point, use of the element "emotion" has singlehandedly become a strategy and all types of factors including sounds, easily attracting colors, provocative tastes, different touchable shapes, seductive fragrances and, sometimes, all types of combinations that form a perception of serenity, are being utilized to reach customer perception, therefore uncharted territories of branding is being explored (Gobe, 2009: 70104). At this point, what you are promising for may be a brand new experience for the consumers.

\section{Transition to Customer-Oriented Dynamic Abilities Concept upon Changing of the Current Marketing Sense as to Enable Sustainable Competition Conditions}

Business management is an evolutionary process, for this reason it continuously needs implementation of new forms and models and during these implementations, what will shape the future of a company's corporate identity is its level of ability for value-enhancing through forming combining its past accumulation of knowledge and its present properties (Teece, 2007: 1346-1347). For this reason, while until recently the general objectives were to increase shares of sale and market, today strategic business units are under spotlight. Especially, under the context of service- 
Pinar Altiok Gürel /International Journal of Research in Business and Social Sciences Vol 3, No 1, 2014. ISSN: $2147-4478$

intense logic which is the standing item of the new marketing sense, the market is regarded as the place wherein sources which carry processes and are processed upon based on their values are integrated and transferred, rather than a place where supply and demand meets, and the company is able to sustain its global competition by continuously expanding its market (Koçak, 2012:77). Considered in this sense requires coordinated work which will include all functions of a business for the purposes of defining customer demands and needs in target markets as to achieve longterm business objectives in modern marketing approach and continuously providing more effective and productive satisfaction in comparison to rivals (Ünnü, 2009:1245). For this reason, companies emphasize the "lifetime value" of a customer and set objectives based on their share of expenditures of that respective customer in a specific time period for a product group (Koçak, 2012:70). As an extension to these approaches, the marketing approach has taken its place as the "optimum marketing management philosophy" and customers are focused within this framework (Ünnü, 2009:1245). Within this direction, the concepts of "market-directional culture", "marketing culture" and "customer culture" are used as synonyms. Being market-directional is defined as the organizational culture which effectually and productively forms behaviors required to create the highest level of value for consumers and the concept of being market-directional are discussed in three dimensions, namely "customer orientation", "being competitor-directional" and "interfunctional coordination" (Ünnü, 2009:1246-1250).

While "customer orientation" implies the requirement of having sufficient level of information about customers in order to create superior value for them, being "competitor-directional" emphasizes the requirement that weak and strong points, long term abilities and strategies of present and possible future rivals of the company must be understood, "interfunctional coordination" must be regarded as coordinated utilization of company resources in order to create the best value for the customer (Ünnü, 2009:1250). At this point, utilization of TQM in order to use innovativeness and provide that the whole organization work with this conscious for the purpose of creating value is important in connection with providing harmony between company departments. Because customer orientation contains how the company can focus on providing a better service for their customers in comparison to competitive offers and integrating and coordinating processes and activities in the whole company for realization of objectives (Bakırtaş-Yılmaz-Özman-Barış, 2013:71). Therefore, it can be said that customer orientation is similar to environmentalist and system approaches where TQM considers the organization and the environment as a whole. In order for the input, process, output and feedback relation of the system approach to translate into a synergic interaction that is provided through use of TQM within CRM, customer orientation stands as a principle parameter. Because, customer orientation requires working in line with all models of input, output and parts (Erkılıç, 2007:53). Within this context, customer orientation will determine production and marketing policies by systematically determining customer demands and expectations.

Formation of a customer-oriented culture within a company enables a reasonable profit for the company while the company itself figures out the types of serving its customers (Bakırtaş-Yılmaz-Özman-Barış, 2013:70). As a result of this effort, utilization of technology and beside, applications named "business-to-business" as to improve effective marketing strategies is exponentially spreading today (Zeithaml \& Bitner \& Gremler, 2009:685). In addition to 
Pinar Altiok Gürel /International Journal of Research in Business and Social Sciences Vol 3, No 1, 2014. ISSN: 2147-4478

technical opportunities, effective communication with a customer also is quite important in this regard. Also needed are equality in information access and transparency in mutual information sharing in order to create a common value, therefore the customer will be able to make a benefit-risk assessment (Koçak, 2012:67). It is an ability for companies to fulfill customer demands and develop new products, and companies create their customer values through these abilities. At this point, dynamic abilities should be perceived beyond traditional abilities. So much so that the ability to position the features and processes required in order to gain competitive advantage within a positive ecosystem can only be possible regulate time factor, current market conditions and technology together in a way that can bring profits to the company (Teece, 2007: 1346-1347). The process of value-creating with the customer depends on operational abilities of the company, starting with information (Koçak, 2012:78).

In the long term, in order to achieve competitive advantage in terms of scale and scope, you need to have a "distinctive" strong feature which renders you different to others (Teece, 2007: 1346-1347). At this point, market orientation is an internal power which is difficult to imitate and a source which earns competitive advantage to a company, standing out in this regard is implementation of the customer oriented strategy which is developed upon organizational response to demands and needs of the market (Ünnü, 2009:1250). Responsive market orientation can be defined as a company initiative directed to fulfilling needs of customers that they express and proactive market orientation, on the contrary, can be defined as a company initiative to fulfill uncovered, covert needs of customers (Ünnü, 2009:1252). That is, proactive market orientation includes exploring, understanding and fulfilling customer needs that have not yet manifested (Koçak, 2012: 73). In order to understand from today the current needs and not-yetmanifested demands and needs of customers, which can be defined as "private demands", activities such as research directed to suppliers and rivals, continuous research activities, re-probing studies and throughout market structure analysis, which require significant investment, are needed. However, in order to define and reshape opportunities to emerge in local and global markets, it is quite important for companies to process these information in a way that they can be turned into advantages within dynamic abilities context (Teece, 2007:1322). Leading customers in order to explore and fulfill their private needs contains a proactive manner (Ünnü, 2009:1252). Gathering market information directed to present and future needs and market orientation for the company to change itself in line with market changes are regarded as operational ability both in service-dominant sense marketing and dynamic abilities (Koçak, 2012:78).

Utilization of these information especially in innovation works is important in terms of creating customer value. Because, due to the reasons that innovation brings competitive advantage to companies and market-orientation is related to innovating power of companies, it is safe to say that these information are quite important in terms of longterm performance (Koçak, 2006:655). The ability of companies to achieve competitive advantage is proportional to their tendency to base their strategies on the concept of creating values containing difference for their customers. Due to this reason, for a company to seize on market opportunities in a way that can provide advantage to itself, it needs to utilize its inner resources in line with its prominent principal abilities. In this direction, according to the dynamic abilities approach which emerged in 2000s, competitive power depends on the ability to respond to dynamic 
Pinar Altiok Gürel /International Journal of Research in Business and Social Sciences Vol 3, No 1, 2014. ISSN: $2147-4478$

environment conditions by integrating, reproducing or recombining internal and external resources (Koçak, 2012:75). That is, dynamic abilities can be expressed as the abilities which enable continuous renewal for the purpose of continuously presenting more effective market offers within dynamic environmental conditions (Koçak, 2012:75). The ability to produce solutions for future demands and needs of customers -which is now possible considering the depth and scope of market research enabled by latest technology- provides companies with the opportunity to sustain their competitive advantages. This situation is an important reason for us to refer to Schumpeter's "destructive creativity" concept. Because possessing new information that can create a difference may externally (or endogenously) create important opportunities (Teece, 2007:1322). In this context, the act of destroying all equilibria for the sake of the better and that this act is a mechanism related to entrepreneurship, which Schumpeter names as "destructive creativity" and qualifies as the reason of transformations that cause industrial leaps, still sustains its validity today (Teece, 2007:1322).

The duration of a period when a company makes use of its competitive power depends on the speed of rivals to obtain the abilities required to implement the respective value-creating strategy (Koçak, 2012:76). In this sense, companies are required to implement strategies that will continuously create new value in line with changing environmental conditions, in order to reach sustainable competitive power (Koçak, 2012:76). With the service-dominant logic, companies are now required to form their strategies based on the starting point that information is the principal source of competitive power. Therefore, implementation of strategies which are both focused on presenting new value for their customers, based on a comprehension of environmental changes and are difficult to imitate by its rivals, will provide sustainable competitive advantage. Because, the competitive power of a company merely depends on the time required to imitate its unique strategy which it has developed (Koçak, 2012:76). When a company forms a competitive advantage by forming a strategy by using its own abilities in a coordinated and integrated way that can enable acting in cooperation with its customers and in a way that it can present them value-creating offers, at that point it will be quite difficult or costly for rivals to imitate such strategy (Koçak, 2012:76). As a result of the open communication which has formed in economic relationships due to globalization, companies are more intensely affected by fast technologic changes, which signifies that companies need to develop their strategic abilities within framework of their dynamic abilities (Teece, 2007: 1346-1347). Here the quality of the relationship to be established is under light. For this reason, modern marketing understanding specifically consists of creating customer value by establishing healthy communication with customers. In this regard, re-structuring of internal resources in a way that market opportunities are detected and new values are presented to customers, can be examined as a resource of competitive power (Koçak, 2012:76). In order for this understanding, which is characterized as customer-oriented, to be institutionalized within the organization and dynamic abilities to be activated as to obtain competitive advantage, it will be wise to start a systematic research in many fields such as industrial sector findings, job analyses, law, organization, innovation, global distribution of free trade and new information sources, in relation to strategic management (Teece, 2007:13461347). All these factors will make sense when the need of change brought in by globalization is correctly perceived and through correctly analyzing the developments related to ever-renewing customer expectations within world 
Pinar Altiok Gürel /International Journal of Research in Business and Social Sciences Vol 3, No 1, 2014. ISSN: 2147-4478

markets. For this reason, external environment is regarded as a resource, rather than an uncontrollable variable, within the service-dominant logic which is the new marketing approach (Koçak, 2012:76). At this point it is surely important to have an entrepreneur spirit in various subjects such as sensing and understanding new opportunities, finding better and different ways and conducting activities in unorthodox ways (Teece, 2007: 1346-1347).

As a result of the effects brought about by globalization, both new marketing paradigms and dynamic abilities focused on resources (and especially information) which procreate operations (Koçak, 2012:61). In this direction, management of tangible and intangible company assets and its corporate and technological means in a way to comply with changing customer expectations and evaluation of present ecosystem for the purpose of creating difference in new product development, design and operation processes exclusively depend on the company's internal dynamic abilities and plays a determining role in success (and/or failure) (Teece, 2007:1320). In this perspective, for companies to sustain their competitive positions within the framework of sustainable profitability, it will be wise for them to structure their strategies through implementation of a set of tools and technics such as total quality management, comparison, time-based competition, outsourcing, partnership, re-engineering and change management (Teece, 2007:1346). Especially with the recent highlighting of service quality and customer satisfaction in service sectors, companies faced an emerging need for TQM applications for purposes of obtaining an effective competitive advantage in global competition arena, adapting to developing market conditions and facilitate change (Balbastre \& Canet, 2011:3). In addition, improving and continuously developing aspects of basic TQM philosophies and principles are made use of business perfection (Balbastre \& Canet, 2011:5).

\section{Innovation Distinguishing in Creating Customer Value within Destructive Creativity Context and its Convenience for Total Quality Management}

"Destructive creativitiy", first suggested by J.A. Schumpeter, means not to use old methods and to find the most effective solutions instead. Schumpeter expressed that innovations will break the balances and stagnancy present in related industrial fields, form movements and leaps and this formation, which he names as "creative destruction" will constitute the basis for economic development (Börü, 2006:7). That Schumpeter's notion of destructive creativity gaining currency again in the Information Age should be regarded in parallel with the fact that information today is a factor that can be utilized in this direction. Because the individual, which stands out in information societies, is to possess a structure which has the information that will provide an advantage to himself, his organization and country, which is able to utilize and share such information which is able to continuously improve and renew itself (ÖrenBiçkes, 2011:68).

Companies are only able to see changes and opportunities in the markets due to utilization of information and in such way they acquire the ability to quickly respond to market needs (Koçak, 2012:63). Since the basic parameter of our day is information and the following technology that has been developing, destructive creativity, in a sense, stands out with its destructive technology aspect. Destructive technologies may be expressed as completely removing present technology and value positioning and creating a new market through presentation of new values to customers (Koçak, 
Pinar Altiok Gürel /International Journal of Research in Business and Social Sciences Vol 3, No 1, 2014. ISSN: 2147-4478

2012:63). Shortening of product life cycles push companies into a more effective and quality competition through continuously and more quickly presenting innovative products and services to the market (Koçak, 2012:63). Companies able to develop new ways in production and presentation win in the global competition environment (Güleş \& Bülbül, 2004:115). As long as product and service innovations fulfill customer needs and expectations, they will continue to be the most important strategic tools of companies (Güleş \& Bülbül, 2004:115). Companies' prospect of producing sustainable competitive power through creating customer value depends on continuously gathering market information using information technology, disseminating and evaluating such gathered information within the organization and thus the ability to quickly respond to present, and more importantly, future consumer needs (Koçak, 2012:63). To see the opportunities uncovered by environmental changes and transforming these opportunities into actions through creative ideas, which other companies cannot (Ören-Biçkes, 2011:84), is an area of differentiation which the companies should use as base. The definitions for market and value creation are changing as radical and leader innovation with destructive technology (Koçak, 2012:63). Since customers are the principle determinator of innovation works, integration of customer needs and expectations with technical activities is a determinant in technical success of a company and the fact that a successful innovation fulfilling a customer's need better than the rivals can, and the quality of such innovation (Güleş \& Bülbül, 2004:122) are determinant factors. According to researches, approximately $70 \%$ of innovations are reached through market needs ((Güleş \& Bülbül, 2004:123). And this, beside many dimensions of itself, is important in terms of portraying the importance of establishing close relationships with customers for the purpose of catching innovations and transforming them into advantages. In this context, aspects of innovation, such as commercializing ideas which can provide competitive advantage to the company, and creating value by meeting customer demands, should be touched upon. Innovative formations vary as product, process, marketing, organization and experience innovations (İncekara, 2013:6) and can provide huge difference and competitive advantage to a company in many fields. Within framework of global competition, innovation means the company's presenting to its customers a value offer which will create a difference for them. Operational resources (information) are resources of principle competition advantage; customer is the factor which always jointly creates the value; companies only suggest values; service is inherently customer oriented and relational; since the concept of creating value comprises communication network all social and economic actors are system integrators; value is uniquely and visually determined by the beneficiary (Koçak, 2012:67). For this reason, experience innovation exclusively has gained a very popular state today. Because with experience innovation, experiences that are not ordinary, not previously thought of and amaze the customer when experienced are used as an important differentiating tool (Incekara, 2013:6). From now on, companies should provide the notion; "this is my brand, I have a role in its formation" rather than "this brand suits me" (Koçak, 2012:70).

The dimension of innovation that is directed to finding new ways to get in touch with customers enables the company to contact faster and more effectively the demand emerging in the market, which reflects on customer value. Because, today the tendency of companies to get new ideas about product design from its customers, to enable trying not-yetlaunched products by certain special customers, in other words, to include their customers in innovation works is a 
Pinar Altiok Gürel /International Journal of Research in Business and Social Sciences Vol 3, No 1, 2014. ISSN: $2147-4478$

result of the efforts for creating and/or increasing customer value upon feedback to be acquired through these activities. Since establishing a close relationship with a customer within scope of TQM will enable acquiring of tips as to future expectations in addition to acquiring information required for fulfilling present customer needs, it will present the company the opportunity to be one step further from its rivals (Güleş \& Bülbül, 2004:123). In other words, innovative works are works utilized for increasing profitability in the long term, moving forward from the foundation of customer value. For this reason, it contacts with customer relations management. In addition, in matrix organizations which stand out in the new economy and implemented by companies rather in certain special projects, the company spends an effort to apply a different and effective organizational method for the purpose of creating customer value. Here the teams formed for conducting an undertaken project are organized in order to reach a common objective rather than as rivals to one another and they exchange energy such as information, material, resource, etc. In this structure, which has a network type organization, the topic of communication requires special sensitivity. Surely the company leader/manager will be under a lot of work in order to prevent such teams from competing and the work from becoming a war of egos. However, due to the active organizing type and working structure paralleling team spirit, there is a strong possibility that future leaders will emerge from among the people tasked in matrix organizations.

The new economy is a molecular economy, that is, company structures dissipate and re-emerge as economic-activity based groups comprised by dynamic individuals and corporations (Tekin and Çiçek, 2005a). Considering they involve potential ideas and formations which can inherently create difference, such matrix organizations also create innovative effects for companies and assert a structure that is directed to provide a sustainable competitive advantage. For companies to increase their creative strengths, creative problem solving technics should be commonly used and obtained results commercially evaluated (İncekara, 2013:11). On this very point, the importance of Total Quality Management applications stand out in the sense that they enable gaining of innovative ideas. Because, works used in TQM such as Fishbone Schemas, Quality Circles, etc. are each one problem solving technic and present an environment which enables contributing and implementing new and original ideas to and in the company. As they contribute the projects jointly developed within the team, they perceive themselves as designers and implementers of the innovations within their company and as part of the change culture and innovativeness, therefore the resistance to a change will be minimized due to such adaptability. TQM regards innovation process as a process that has to be achieved and emphasizes that it requires an interfunctional effort (Güleş \& Bülbül, 2004:122). Since recognizing employees, asking their opinions while prospective projects are built up will instill a sense of deciding for own future, this situation improves the conscience to jointly undertake the requirements of change. Seeing the effects of one's own contribution on the company future is an important motivator supporting success. In this regard, while total quality applications present an environment suitable for development of new technologies, they also contribute to opening of new and innovative production fields. Innovation is an interfunctional and integrated activity (İncekara, 2013:4) which involves all company departments and employees (İncekara 2013:3). 
Pinar Altiok Gürel /International Journal of Research in Business and Social Sciences Vol 3, No 1, 2014. ISSN: 2147-4478

TQM provides for a more successfully managed innovation process by enabling establishment of an interfunctional objective commonality, including customer demands into the process and timely correcting errors throughout stages, therefore providing organization-wide learning (Güleş \& Bülbül, 2004:121). For this reason, synchronous realization of both TQM and innovation works will form a synergic strength, therefore providing companies important opportunities in obtaining competitive advantage (Güleş \& Bülbül, 2004:127). However, it should be exclusively considered that the importance of ownership rights to applications that create differentiation and are difficult to imitate, and know-how agreements, for the purpose of obtaining competitive advantage must be comprehended (Teece, 2007:1320). The continuous improvement culture, which is the basic principle of TQM, by preparing an infrastructure suitable for innovation works and customer value creation, will provide a convenient working area for obtaining competitive advantage.

\section{The Consistent Relationship between Total Quality Management and Human Resources Management Providing Competitive Advantage}

Considering that business companies competing within the market set out with technically same conditions, it is fitting to say that the most important factor to affect success is the human being. Technology and products may immediately be imitated, however employee loyalty, knowledge of job, problem resolving skills and team spirits cannot be taken over by other companies (Sabuncuoğlu, 2011:25). For this reason, the basic foundation of competition is human resources and Human Resources Management (HRM) carries the quality of a multidimensional function for an organization tending to achieve total quality (Sabuncuoğlu, 2011:25). Since the fundamental factor TQM is human resources -this very important factor-, the relationship between TQM and HRM is worth mentioning at this point. Processes, systems and methods providing goods and services to customers are developed, implemented, controlled and preserved by humans (Sabuncuoğlu, 2011:25). For this reason, HRM forms the backbone of a model in reaching total quality, working in integration with all other organizational units and levels in a multi-functional order. Within this direction, it will be a correct statement to say that there is a consistent relationship between basic TQM principles and HRM. In this post-modern world of today, management science is to reach its objectives by utilizing the intellectual capital, which is the most important asset of a company, and using methods that suit and value the human being. For this reason, organizations grasped the importance of implementing applications which regard the human being as the most important means to increasing organizational performance. Customers, employed personnel, intermediary institutions, public offices, banks and finally, all social levels for the company is responsible, mean to work together with people. For this reason, the fact that a company both plans for today and forms strategies for the future while investing in human-oriented approaches will form an interaction which will always increase customer value. Moving forward from the fundamental point that the most effective way to direct people is to trust in them, TQM displays the value given to people by empowering them (Güleş \& Bülbül, 2004:124).

Considering that effective communication is greatly important in the global competition environment, the structure of total quality approach that values human beings, rewards valuable ideas and emphasizing effective listening provides 
Pinar Altiok Gürel /International Journal of Research in Business and Social Sciences Vol 3, No 1, 2014. ISSN: 2147-4478

an environment that is convenient establishing a healthy relationship. One of the fundamental principles of TQM is customer-orientation. Two most important factors in formation of a customer-oriented organization are; a corporate database and a qualified workforce which takes quality as base in all customer relations and adopts it in all work stages. A customer-oriented organization is to fulfill four important stages. These stages (Bakırtaş et al., 2013:71) can be summarized as; "Joint Coordination" which will be implemented through formation of a corporate database that includes information gathering from all customer contact points and then standardization of such information, "Serial Coordination" which consists of analyzing and transformation into analytical data the customer information stock, "Symbiotic Coordination" which involves a set of analyses from measurement of results of activities directed towards predicting and customer behaviors and intervening as to alter such behaviors to evaluation of feedback from such activities, and "Complementary (Integral) Coordination" which requires continuous training of the personnel working to enable the organization's use of the information gathered in daily customer interactions. It must not be forgotten that the employees who are internal customers of the company play an important role in obtaining customer loyalty (Bakırtaş et al., 2013:75). TQM is a way of management which values customer expectations above everything in order to increase satisfaction of internal and external customers and organizes its activities around such expectations (Güleş \& Bülbül, 2004:123). In this respect, as an extension of customer-oriented sense, the fundamental principle adopted by HRM is to firstly ensure satisfaction of employees as internal customers, and then, as a further extension, ensure full satisfaction of external customers, therefore having provided total quality both for employed personnel and all other stakeholders, as a requirement of customer orientation. By satisfying internal customers, TQM brings the ability to fully satisfy the needs of external customers, into the company (Güleş \& Bülbül, 2004:123). It is clear that the objective of total quality that "working with zero errors in all company processes and therefore realizing customer satisfaction in full capacity" will be enabled in a corporate culture climate wherein quality has been institutionalized. For this reason, all units within a company are to be organized in a formation based on customer-oriented thinking. Again, the need for a corporate culture which will regulate personnel behavior patterns to shape based on the sense of belonging to the corporation, for team works to spring from such structure to be successful, arises.

The fact that total quality approach is a management system which features team work requires that all organization within a company be structured based on this style of working. Education sessions required for teaching to employed personnel the problem solving technics directed to total quality is again under responsibility of human resources. Formal and informal information flows and sharing stand out in total quality works where communication is vitally important. Working towards continuous improvement in processes is taken as base in reaching total quality. The technics utilized in TQM are required in order to support the continuous improvement process (Balbastre \& Canet, 2011:5). Training the employed personnel as open to innovations positively reflect on continuous improvement activities. A work personnel profile able to realize customer satisfaction and organizational objectives is important for total quality management. The effects of advanced quality management approaches on human resources, and consecutively employment planning, must also be considered (Balbastre \& Canet, 2011:5). 
Pinar Altiok Gürel /International Journal of Research in Business and Social Sciences Vol 3, No 1, 2014. ISSN: $2147-4478$

The structure of TQM which enables multi-directional communication ensures improvement of processes especially in matrix organizations wherein horizontal, vertical and cross organizations are used together, through the personnel expressing themselves and participating in management. The objective of providing customer satisfaction to its full extent should be reflected on work designs, therefore authorizations should be made within the company based on the objective of quality, and to this end, specialty areas of employees should be used in a way to increase productivity and quality. In addition, organizing performance assessment technics used in HRM in a way that will feature quality and service will be wise for realization of the total quality objective. Conducting performance assessments on personnel utilizing especially technics such as "360-Degrees Performance Appraisal" and "Performance Prism Approach" might also turn out wise. At its foundations, TQM involves activities such as motivating persons, directing persons, educating people to increase their knowledge and skill levels, rotation and business enriching, which aim to increase the quality of human resources (Güleş \& Bülbül, 2004:124). For this reason, rewarding success and enabling fair promotion opportunities are procedures that will contribute company institutionalizing of total quality spirit in terms of human resources. While increasing the importance attached to human health in companies will increase quality, it will also improve the sense of belonging, therefore ensuring comfortable expression of creative ideas from personnel and ultimately contributing the process of innovation. Decreasing workplace conflicts as a result of the common resolution understanding brought about by the team work is another contribution of total quality applications. Senior management staying in continuous dialogue as a result of procedures implemented in line with total quality spirit will provide fluent and effective in-company communication.

\section{Conclusion and Evaluation}

The concept of total quality, with its wide dimensions, has today taken its place within principal marketing strategies and undertaken determining roles in forming corporate culture and in work processes of companies. Due to TQM being a customer oriented management strategy that requires comprehensive and systematic approach, it has strong relations with CRM. Fast changes and transformations brought by globalization caused handling market conditions in different perspectives and in this direction, TQM approaches being utilized within the field of CRM gained currency together with a new conscience which will provide sustainable global competitive advantage. A human-oriented approach, TQM aims to reflect its strategy on company vision and training first the personnel and then all stakeholders of a company as individuals as problem resolvers and ultimately ensuring long-term customer satisfaction, through continuous improvement, processes management, customer orientation, human resources management and full participation implementations. Due to its impacts that contribute problem solving, aim to minimize errors and increasing personnel motivation by widening their creative thinking field, TQM brings competitive advantage in terms of productivity increase in a business. Recent use of environmental ethics and management, a different subject, as a marketing strategy, in order to provide an opportunity to increase company skills in fields of innovation and change and therefore to create a difference in sustainable global competition, is one dimension of the TQM content. Upon the realization that TQM applications foster the positive effects on the social system which has been sustained in companies, attention in studies of CRM, which is an important business strategy that we can describe as the 
Pinar Altiok Gürel /International Journal of Research in Business and Social Sciences Vol 3, No 1, 2014. ISSN: $2147-4478$

combination of strategies and technologies which re-structure a whole organization based on customer satisfaction, has been turned to the advantageous position of TQM. Determination of behaviors, values and information of customers within the global market, who are differentiated from one another, turning these information into meaningful parameters and ultimately obtaining acquisitions that can increase company effectiveness depend on correct implementation of CRM. A very thorough analysis of customer demands and expectations and taking role within the competition by forming a strong quality understanding is required to this end. The new dimensions brought about by globalization into the world market necessitated that companies develop strategies that can welcome the change in order to stay competitive. It is also obvious that the structure of TQM which is in line with change management will provide an advantage in formation of customer-oriented visions, for public and private sectors. In addition, the recently current EFQM Excellence Model which carries a more integrated structure within quality field is quite adequate for improving company performance and contribute to sustainable competitive advantage. Information and skills standing out as the most important dynamic resources in the new economy has shifted the power center into this field and the individual, carrying the required equipage in this regard, has become the principal economic input. Therefore, with post-modern management technics embracing approaches focusing on the individual able to manage information, designing of customer relations and total quality approaches in such a way to provide sustainable competitive advantage through orientation at the very beginning when organization structures are being formed, has become the fundamental understanding which directs marketing policies. As a result of the ease of communication brought by technology providing fast access to information and service for consumers and the increasing education level, the information asymmetry between companies and customers changed, which resulted in the concept "customer lifetime value" taking a strategic role for companies. To this end, customer orientation in CRM and in addition, formation of a proper database, translating these data into meaningful information and effectively utilizing such information became prominent elements of sustainable competitiveness. In the recent time especially the proactive market orientation has been regarded as the capacity to predict and fulfill future expectations of consumers, for the possible opportunities in the global market, and has become a dynamic ability for companies in this regard.

A company is as strong as its dynamic abilities are sustainable. For this reason, studies directed to new value presentations causing technological leaps have accelerated and Schumpeter's notion of "destructive creativity" has carried over to today. Especially in service-producing sectors, due to service quality and customer satisfaction being featured much more recently, companies felt an immense need for TQM applications for the purpose of gaining global competitive advantage. Company-developing and ever-improving aspects of TQM applications are utilized for business perfection models. Efforts to present new values to customers within the global competition brought innovative works to the agenda. Having positioned their strategies in a way that they are able to predict and immediately respond to future needs of customers, such companies are distinctly gaining the advantage in global competition. In this context, acquiring customer information, integrated solution implementation for increasing customer value, following up multi-row demand chain, integration to resource chain and correct structuring of customer contact points and many similar fields require close relations with CRM. Due to structures of technics 
Pinar Altiok Gürel /International Journal of Research in Business and Social Sciences Vol 3, No 1, 2014. ISSN: $2147-4478$

utilized in TQM enabling new and merchantable original ideas, implementing TQM in coordination with CRM is a factor which translates into global competitive advantage. Innovative and change culture-compatible CRM applications support innovation for public and private sectors and enable interfunctional integration. Therefore, an infrastructure suitable for creating customer value, is formed. Also it should be mentioned that the consistencyfostering effect between the customer-oriented understanding of TQM and CRM is worth emphasizing.

The supportive relationship in areas such as personnel adopting the idea that he can satisfy external customers by himself being perceived as an internal customer, reflections of the structure which supports team work on corporate culture, formal and informal information flow contributing to the working personnel's preparation of change and innovations and many similar areas, reflect on the competitive advantage of a company. TQM realizes the objective of ensuring customer satisfaction by enhancing companies' capacity to catch up on innovations and opportunities and the areas wherein the company would be able to acquire competitive advantage in terms of motivating human resources. In addition to enhancing information sources, TQM provides the opportunity to develop new products in shorter time periods, with lower cost and at higher quality. While quality gets more and more features among the factors increasing competitive strength, the understanding of TQM which is based on stakeholder participation and continuous improvement has also been spreading. As long as the integration of world economies increases, scope and intensity of competition has been changing on a vast scale. In the new economy where sustainable competition factors are in predominant roles, strategic approaches towards conducting both TQM and CRM in relevance contribute unique, nonimitable and distinctive advantages to companies due to their human-oriented structure, therefore bringing in longterm positive effects within global competition field. Therefore, TQM, beside its impacts it has constructed on basic parameters of CRM, such as customer orientation, team works, working towards continuous process improvement and management participation, is also becoming an important means for economic structuring in the new age with its participative democratic structure, therefore providing sustainable global competitive advantage to companies.4.

\section{References}

Aktan, C. C. (2013). Implementation of Total Quality Management in Higher Education., http://www.canaktan.org/egitim/universite-reform/toplam-kalite.htm., pg:1-3., Date Accessed:16.09.2013.

Altiok, P. (2013). An Evaluation on the Importance of Entrepreneurial Personality on Economical Development in the Information Age, International Association of Social Science Research., European Conference on Social Science Research., Marmara University, İstanbul., June 19-21, 2013, pp:1-8.

Argüden, Y. (2013)., EFQM Excellence Model and Balance Score Card Institution Score Card., http://kobitek.com/efqm_mukemmellik_modeli_ve_balanced_scorecard_kurum_karnesi., Date Accessed:24.08.2013.

Bakirtaş, H., A. Yilmaz., M. Özmen \& G. Bariş (2013). Customer Relations Management., R.T. Anadolu University Publications No:3001., 1.Bask1., Eskişehir., January 2013., http://eogrenme.anadolu.edu.tr/eKitap/PZL208U.pdf., Date Accessed: 23-26.08.2013. 
Pınar Altiok Gürel /International Journal of Research in Business and Social Sciences Vol 3, No 1, 2014. ISSN: 2147-4478

Balbastre., F. B. \& M.T. Canet-Gine. (2011). The Strategy Formation Process in the EFQM Excellence Model: A Critical Review and New Perspectives., Total Quality Management and Business Excellence (impact factor: 0.59). 07/2011; 22:727-742. DOI:10.1080/14783363.2011.585773., http://www.researchgate.net/publication/233340593_The_strategy_formation_process_in_the_EFQM_Excellence_M odel_a_critical_review_and_new perspectives (19.08.2013)., Date Accessed: 24.05.2013.

Börü, D. (2006). Entrepreneurship Education., Marmara University Publication No:733, Social Sciences Institute Publication No:21., İstanbul., 2006.

Durukan, T. (2006). The History of Entrepreneurship and the Importance of Entrepreneurship in the 21st Century., Journal of Entrepreneurship and Development., Volume:1, Issue:2., December 2006., pp:25-37.

Gobe, M. (2009). Emotional Branding: The New Paradigm For Connecting Brands To People (Updated and Revised Edition)., Allworth Prepg:Canada., Printed:USA., 2009.

Güleş, H. K. (2004)., Contributions of Information Technologies in Customer Relations Management, Selçuk University, Social Sciences Institute Magazine, Issue:12, 2004, pg:231-243., http://www.sosyalbil.selcuk.edu.tr/sos_mak/makaleler/Hasan $\% 20 \mathrm{~K} \% \mathrm{C} 3 \%$ BCr\%C5\%9Fat $\% 20 \mathrm{G} \% \mathrm{C} 3 \% 9 \mathrm{CLE} \% \mathrm{C} 5 \% 9$ E/231-243.pdf., Date Accessed: 15.09.2013.

Güleş, H. K. \& H. Bülbül (2004)., Contributions of Total Quality Management on Innovation Works in Companies, Gazi University Economy and Administrative Sciences Faculty Magazine, Volume:6, Issue:1, Spring 2004., ss.115129., http://iibfdergisi.gazi.edu.tr/index.php/iibfdergisi/article/view/279/269., Date Accessed:15.09.2013.

İncekara, A. (2013). Energy, Innovation and Creative Entrepreneur., http://www.iav.org.tr/makale.asp?id=15., Date Accessed: 02.09.2013.

Kalder (Turkish Quality Association) (2013). EFQM Excellence Model., http://www.kalder.org/kalderhakkinda.aspx?id=18., Date Accessed: 24-25.08.2013.

Kiliç, R. \& E. Türker (2005)., The Importance Of Process Management In Efqm Excellence Model., Mevzuat Magazine., Year:8, Issue:87, March 2005., http://www.mevzuatdergisi.com/2005/03a/01.htm., Date Accessed:24.08.2013.

Koç, E. (2013). Consumer Behaviors and Marketing Strategies., Seçkin Publication, İstanbul, 2013.

Koçak, A. (2012). Reconsidering Marketing for Sustainable Competition, Çankırı Karatekin University, Economics and Administrative Sciences Faculty Magazine., Volume: 2, Issue: 2, Fall 2012., pp: 61-84.

Mucuk, İ. (2012). Fundamental Business Knowledge. Türkmen Kitabevi., 6th Issue, 2012, İstanbul.

Mucuk, İ. (2009). Marketing Principles. Türkmen Kitabevi, 17. Issue, 2009, İstanbul.

Odabaşi, Y. (2006). Why Value Must Be Created For Customers., İş\&Güç Magazine., Issue:4, 01/2006., s:18., http://yavuzodabasi.wordpress.com/category/isguc-degisi/., Date Accessed:15.08.2013.

Ören, K. \& B. Mehmet. (2011). Effects of Personal Traits on Entrepreneurship Potential (A Research Conducted on Higher Education Students in Nevşehir), Süleyman Demirel University Economics and Administrative Sciences Faculty Magazine., Year:2011, Volume:16, Issue:3, pp: 67-86., Online:http://sablon.sdu.edu.tr/fakulteler/iibf/dergi/files/2011-3-5.pdf. 
Pınar Altiok Gürel /International Journal of Research in Business and Social Sciences Vol 3, No 1, 2014. ISSN: 2147-4478

Rushton, A., Oxley, J. \& Croucher, P. (2000)., The Handbook of Logistics and Distribution Management., Kogan Page., 2nd Edition., London.

Sabuncuoğlu, Z. (2011). Human Resources Management, Beta Publications, İstanbul,2011.

Teece, D. J. (2007). Explicating Dynamic Capabilities: The Nature And Microfoundations Of (Sustainable) Enterprise Performance., Strategic Management Journal., Strat. Mgmt. J., 28: 1319-1350 (2007)., Published Online 7 August 2007 in Wiley InterScience (www.interscience.wiley.com) DOI: 10.1002/smj.640., Received 16 February 2004; Final revision received 20 June 2007., Copyright 2007, John Wiley \& Sons, Ltd., Wiley Online Library., http://onlinelibrary.wiley.com/doi/10.1002/smj.640/pdf., Date Accessed: 11.09.2013.

Özmen, Ş. \& U. Özmen (2002). The New Twin of Marketing in 21st Century Marketing Paradigm: Technology., pg:18., http://www.suleozmen.com/teblig_sunumlar/10paz_ikizi_teknoloji_sule_ozmen.doc., Date Accessed: 15.09.2013.

Taşkın, E.., (2004)., Customer Relations Training., Papatya Publications., İstanbul.

Tekin, M. \& Ç. Ercan. (2005a). Information Society and Information Economy in the Information Age, Online:http://bilgitoplumu.blogspot.com/2006/10/bilgi-anda-bilgi-toplumu-ve-bilgi.html\#_ftn35.

Tekin, M. \& E. Çiçek., (2005b). A Different Approach in Achieving Competitive Advantage in Business Companies:Value-Based Marketing., 5th International Production Researches Symposium, Istanbul Commercial University, 25-27 November 2005., http://www.iticu.edu.tr/uploads/kutuphane/pdf/uas/M01009.pdf., ss.63-68., Date Accessed: 23.08.2013.

Turan A. E. (2007). Discussing Total Quality Management Principles Management within Management Approaches Context., GAU Journal of Social \& Applied Sciences 2 (4), Bahar 2007., pp:51-62., http://www.gau.edu.tr/PDFFiles/JSAS_002_04_PDF/JSAS_002_04_05_Erkilic.pdf., Date Accessed:14.08.2013.

Ünnü, N. \& A. Ayyildiz (2009). The Importance of Market Orientation and Authentic Leadership in Political Marketing., Ege University Economics and Administrative Sciences Faculty / Ege Academic Review (Economy, Business, International Relations and Political Science) Magazine., Year:2009., Issue: 4., Volume: 9., pp:12431273., http:/www.onlinedergi.com/eab/arsiv/arsivDetay.aspx?yil=2009\&peryot=4., Date Accessed:03.09.2013.

What is 80/20 Rule (2013). What is 80/20 Rule, Pareto's Law, Pareto Principle, www.80-20presentationrule.com, 2008., Date Accessed:02.09.2013.

Vikipedia (2013)., 14 Principles of Deming., http://tr.wikipedia.org/wiki/Deming'in_14_\%C4\%Bolkesi., Date Accessed: 15.08.2013.

Zeithaml, V. A., Bitner, M. J. \& Gremler, D. D. (2009) Services Marketing, 5th Edition (International Edition)., New York, Mc Graw-Hill. / Irwin, 2009.

Zerenler, M., Türker, N. \& Esen, Ş. (2006). The Relationship of Global Technology, Research \& Development and Innovation, Selçuk University Social Sciences Institute Magazine, (17), pp: 653-667. http://www.sosyalbil.selcuk.edu.tr/sos_mak/makaleler/Muammer\%20ZERENLER\%20$\% 20$ Necdet $\% 20$ T $\%$ C3\%9CRKER $\% 20$ \%20Esen\%20\%C5\%9EAH\%C4\%B0N/ZERENLER,\%20MUAMMER\%20VD.pdf., Date Accessed:03.09.2013. 